\title{
Measuring the usage of preferential tariffs in the world
}

\begin{tabular}{|l|l|}
\hline 著者 & $\begin{array}{l}\text { Hayakawa Kazunobu, K mur a Fukunar i , } \\
\text { Laksanapanyakul Nut t amut }\end{array}$ \\
\hline 権利 & $\begin{array}{l}\text { Copyr i ght s 日本貿易振興機構 (ジェトロ ) アジア } \\
\text { 経済研究所 / I nst i t ut e of Devel opi ng } \\
\text { Economes, Japan Ext er nal Tr ade Organi zat i on } \\
\text { ( I DE- JETRO) ht t p: //nww. i de. go.j p }\end{array}$ \\
\hline $\begin{array}{l}\text { j our nal or } \\
\text { publ i cat i on ti t l e }\end{array}$ & I DE Di scussi on Paper \\
\hline vol une & 595 \\
\hline year & 2016 - 04 01 \\
\hline URL & ht t p: //doi . or g/10. 20561/00037586 \\
\hline
\end{tabular}




\title{
INSTITUTE OF DEVELOPING ECONOMIES
}

IDE Discussion Papers are preliminary materials circulated

to stimulate discussions and critical comments

\section{IDE DISCUSSION PAPER No. 595}

\section{Measuring the Usage of Preferential Tariffs in the World}

Kazunobu HAYAKAWA*, Fukunari KIMURA, Nuttawut LAKSANAPANYAKUL

April 2016

\begin{abstract}
The preference utilization ratio, i.e., the share of imports under preferential tariff schemes out of total imports, has been a popular indicator for measuring the usage of preferential tariffs vis-à-vis tariffs on a most-favored-nation basis. A crucial shortcoming of this measure is the data requirements, particularly for import value data classified by tariff schemes, which are not available in most countries. This study proposes an alternative measure for preferential tariff utilization, termed the "tariff exemption ratio." This measure offers the unique advantage of needing only publicly available data, such as those provided by the World Development Indicators, for its computations. We can thus calculate this measure for most countries for an international comparison. Our finding is that tariff exemption ratios differ widely across countries, with a global average of approximately $50 \%$.
\end{abstract}

Keywords: Preferential trade agreements; general system of preferences; utilization of preferential arrangements; tariff revenues

JEL classification: F15, F53

* Researcher, Economic Geography Studies Group, Inter-disciplinary Studies Center, IDE (kazunobu_hayakawa@ide.go.jp) 
The Institute of Developing Economies (IDE) is a semigovernmental, nonpartisan, nonprofit research institute, founded in 1958. The Institute merged with the Japan External Trade Organization (JETRO) on July 1, 1998. The Institute conducts basic and comprehensive studies on economic and related affairs in all developing countries and regions, including Asia, the Middle East, Africa, Latin America, Oceania, and Eastern Europe.

The views expressed in this publication are those of the author(s). Publication does not imply endorsement by the Institute of Developing Economies of any of the views expressed within.

\section{INSTITUTE OF DEVELOPING ECONOMIES (IDE), JETRO}

\section{3-2-2, WAKABA, MIHAMA-KU, CHIBA-SHI}

\section{CHIBA 261-8545, JAPAN}

(C)2016 by Institute of Developing Economies, JETRO

No part of this publication may be reproduced without the prior permission of the IDE-JETRO. 


\title{
Measuring the Usage of Preferential Tariffs in the World
}

\author{
Kazunobu HAYAKAWA ${ }^{\# \S}$ \\ Inter-disciplinary Studies Center, Institute of Developing Economies, Japan \\ Fukunari KIMURA \\ Faculty of Economics, Keio University, Japan
}

Nuttawut LAKSANAPANYAKUL

Science and Technology Development Program, Thailand Development Research Institute, Thailand

\begin{abstract}
The preference utilization ratio, i.e., the share of imports under preferential tariff schemes out of total imports, has been a popular indicator for measuring the usage of preferential tariffs vis-à-vis tariffs on a most-favored-nation basis. A crucial shortcoming of this measure is the data requirements, particularly for import value data classified by tariff schemes, which are not available in most countries. This study proposes an alternative measure for preferential tariff utilization, termed the "tariff exemption ratio." This measure offers the unique advantage of needing only publicly available data, such as those provided by the World Development Indicators, for its computations. We can thus calculate this measure for most countries for an international comparison. Our finding is that tariff exemption ratios differ widely across countries, with a global average of approximately $50 \%$.
\end{abstract}

Keywords: Preferential trade agreements; general system of preferences; utilization of preferential arrangements; tariff revenues

JEL Classification: F15; F53

\footnotetext{
\# Corresponding author: Kazunobu Hayakawa; Address: IDE-JETRO, Wakaba 3-2-2, Mihamaku, Chiba, Chiba Prefecture, 261-8545, Japan. Tel: 81-43-299-9500; Fax: 81-43-299-9724; E-mail: kazunobu_hayakawa@ide-gsm.org.

${ }^{\S}$ We would like to thank Tatsuo Hatta, Hiroshi Ohashi, Hiroshi Mukunoki, Arata Kuno, Kozo Kiyota, and the seminar participants at the Asian Growth Research Institute, JETRO Bangkok, Hokkaido University, and the Japan Society of International Economics. This work was supported by JSPS KAKENHI Grant Number 26705002.
} 


\section{Introduction}

The most-favored-nation (MFN) principle, as a backbone of policy discipline for the General Agreement on Tariffs and Trade (GATT) and the World Trade Organization (WTO), has been strictly implemented, particularly for import tariffs. The privilege of enjoying MFN status has provided a strong incentive for developing countries to participate in GATT/WTO. Tariff reductions under WTO, however, have not been well advanced in the Doha Development Agenda. As a result, most countries around the world have started to aggressively exploit the "exceptions" to the MFN principle.

There are three major forms of exception to the MFN principle on tariffs. The first is regional trade agreements (RTAs), including free trade areas and customs unions. GATT Article XXIV allows RTAs as exceptions to the MFN principle under loosely specified conditions. The number of RTAs has increased explosively since the 1990s. The second exception is the generalized system/scheme of preferences (GSP). Under the initiative of the United Nations Conference on Trade and Development (UNCTAD), GSP started in 1970 as another exception to the MFN principle so that developed countries can grant preferential status to developing countries' exports. The third exception includes various special trade arrangements for export processing zones, offshoring operations, and duty-drawback systems.

For both academics and policymakers, it is important to quantify the extent of such preferential tariff utilization. A traditional trade economist supporting the MFN principle may want to know the extent to which actual trade deviates from the MFN principle. Policymakers may, once the GSP or RTAs are prepared, certainly want to quantify the extent to which the preferential scheme is actually utilized. The utilization of preferential tariffs under RTAs and GSP is not automatic; preferential tariffs are applied only when imported products clear the rules of origin. As a result, some exporters may still trade under general tariff schemes, such as MFN rates, if they consider it difficult or costly to prove their products' origins.

We have tried to measure preferential tariff utilization in various ways. A typical measure is the share of trade that uses preferential tariffs out of total trade. ${ }^{1}$ Several studies have reported such shares for various preferential schemes: (1) GSP granted by the European Union (EU) and the United States (US) to developing countries in the agricultural goods sector (Bureau et al., 2007), (2) preferences granted by the EU to non-least-developed African, Caribbean, and Pacific countries under the Cotonou

\footnotetext{
${ }^{1}$ Some variations exist in the measure of preference utilization. One issue is whether or not to exclude trade in products that are ineligible for preference schemes in the denominator. For more details, see Keck and Lendle (2012).
} 
Agreement (Francois et al., 2006; Manchin, 2006), (3) GSP granted by the US to 143 countries (Hakobyan, 2015), (4) bilateral and multilateral RTAs when exporting from Thailand to Japan (Hayakawa, 2014), and (5) RTA schemes applicable to exports from ASEAN countries to Korea (Hayakawa et al., 2014). For example, Hayakawa et al. (2014) showed that for exports to Korea in 2011, the utilization ratio of the ASEANKorea free trade agreement was 74\% for Brunei, 63\% for Indonesia, 67\% for Cambodia, 44\% for Lao PDR, 96\% for Myanmar, 35\% for Malaysia, 42\% for Philippines, 35\% for Thailand, and 78\% for Vietnam.

A crucial shortcoming of the preference utilization ratio lies in the difficulty in obtaining the necessary data. Its computation requires data on trade values classified by tariff schemes such as RTA, GSP, and MFN. Almost all countries other than the US and those in the EU do not publicly disclose such data. ${ }^{2}$ Such data are available only for limited purposes, such as pure academic research. As a result, the extent of preference utilization variation across countries remains unknown.

This study proposes a powerful alternative measure of preferential tariff utilization in each country's imports. ${ }^{3}$ It offers the unique advantage of only requiring publicly available data in its computation. Specifically, we employ data on total government revenues from import duties. Such data are often used for computing the "tariff burden ratio," which can be a proxy for import duties. It is computed by dividing total government revenues from import duties by total imports. ${ }^{4}$ Our measure of preference utilization is (one minus) the share of "actual government revenues from import duties" in "the hypothetical total government revenues from import duties," the latter of which are the import-weighted average of MFN rates multiplied by total imports. Namely, it measures the share of exempted duties out of the total tariff revenues that would have been obtained if all imports had been under MFN rates. Naturally, the utilization of RTA or GSP schemes raises the exempted duties. In addition, if a country introduces other tariff exemption schemes, such as duty drawbacks for re-exports, the magnitude of exempted duties becomes larger in that country. We call this measure the "tariff exemption ratio" and compute it by employing only publicly available international databases, i.e., World Development Indicators (WDI) and the OECD iLibrary. Thus, this measure can be calculated for almost all countries in the

\footnotetext{
${ }^{2}$ Recently, the Japanese Government also disclosed data on imports under RTA schemes but not on those under the GSP scheme.

${ }^{3}$ We focus on the import side because it is generally difficult to measure preference utilization on the export side. For more details, see Hayakawa et al. (2013).

${ }^{4}$ Also, revenue data are employed to examine the relationship between tax revenue and trade liberalization in some studies (Khattry and Rao, 2002; Agbeyegbe et al., 2006; Baunsgaard and Keen, 2010; Hisali, 2012).
} 
world for either cross-country or time-series comparisons.

Our tariff exemption ratio can be interpreted as a proxy for the extent of preference utilization for imports of products with positive MFN rates. By definition, the utilization of preferences for products with zero MFN rates does not affect the tariff exemption ratio because it is based on the extent to which import duties are exempted by importing under preferential rates compared with importing under MFN rates. After all, from the viewpoint of measuring the utilization of preference schemes, the preference utilization ratio works better because it identifies the preference utilization based only on whether or not such preference schemes are in fact utilized. On the other hand, the tariff exemption ratio is a better measure from the viewpoint of gauging the extent of giving tariff advantages to preference partners or how far preference partners enjoy tariff exemptions. In this sense, these two measures will be complementary.

We conduct several analyses on the calculated tariff exemption ratios. First, as we can access the necessary data for Thailand, we calculate both the preference utilization ratio and the tariff exemption ratio for comparison. The results indicate that when computing these ratios for products with positive MFN rates in Thailand, their values become almost identical. Second, computing the tariff exemption ratio for a large number of countries (112 countries), we take an overview of differences in preference utilization across countries. Third, we examine the correlation of the tariff exemption ratio with various elements. For example, because countries conducting large transactions with RTA partners are supposed to use the tariff exemption scheme more, the tariff exemption ratio should be positively correlated with the share of total intra-block imports. The tariff exemption ratio should also have a positive correlation with preference margins (i.e., the difference between MFN and preferential rates). The aforementioned studies on the preference utilization ratio have consistently shown that for imports by each specific country, the extent of preference utilization is positively associated with preference margins. Our result confirms that such a positive relationship exists in a large number of countries.

The rest of this study is organized as follows. The next section provides the specific definition of our tariff exemption ratio. In Section 3, employing data on imports according to tariff schemes for Thailand, we examine the performance of this measure by comparing it with the preference utilization ratio. Section 4 computes tariff exemption ratios for a large number of countries. Section 5 examines the correlation of our tariff exemption ratio with various elements. Section 6 concludes. 


\section{Tariff Exemption Ratio}

We consider the utilization of preferences for a country's total imports, not its imports from a specific country. When measuring the utilization of preferences, the following measure is often employed (country subscript is omitted):

$$
V \equiv \frac{\sum_{i} I_{i}^{P}}{\sum_{i} I_{i}^{M}+\sum_{i} I_{i}^{P}}
$$

where $I_{i}{ }^{M}$ and $I_{i}{ }^{P}$ are import values of product $i$ under MFN schemes and preferential schemes, respectively. This measure, called the "preference utilization ratio," shows the share of preferential imports out of total imports. On the other hand, the measure proposed in this paper is called the "tariff exemption ratio" and is given by

$$
E \equiv 1-\frac{\sum_{i} t_{i}^{M} I_{i}^{M}+\sum_{i} t_{i}^{P} I_{i}^{P}}{\sum_{i} t_{i}^{M}\left(I_{i}^{M}+I_{i}^{P}\right)},
$$

where $t_{i}{ }^{M}$ and $t_{i}{ }^{P}$ are MFN tariff rates and preferential rates, respectively. While the numerator in the second term shows total government revenues from import duties, the denominator indicates MFN rates multiplied by total imports. In other words, the latter shows the total tariff revenues that would have been obtained if all imports had occurred under MFN rates, i.e., the hypothetical tariff revenues earned for all imports.

We can get a clearer insight on the tariff exemption ratio by further simplifying the above formulation as follows:

$$
E=\frac{\sum_{i}\left(t_{i}^{M}-t_{i}^{P}\right) I_{i}^{P}}{\sum_{i} t_{i}^{M}\left(I_{i}^{M}+I_{i}^{P}\right)} .
$$

The difference between MFN and preferential rates is called a "tariff margin" or a "preference margin." The numerator shows how much tariff revenue is lost by importing under preferential schemes. As a result, it measures the share of exempted duties out of total potential tariff revenue. ${ }^{5}$

This measure seems to be well related to the preference utilization ratio. Indeed, it is easily proven that $E$ is completely equal to $V$ if $t_{i}{ }^{P}=0$ and $t_{i}{ }^{M}=t$ for all $i$. If MFN rates differ by products, the difference between these two measures becomes

$$
E-V=\frac{\sum_{i} I_{i}^{M} \sum_{i} t_{i}^{M} I_{i}^{P}-\sum_{i} I_{i}^{P} \sum_{i} t_{i}^{M} I_{i}^{M}}{\left(\sum_{i} t_{i}^{M} I_{i}^{M}+\sum_{i} t_{i}^{M} I_{i}^{P}\right)\left(\sum_{i} I_{i}^{M}+\sum_{i} I_{i}^{P}\right)} .
$$

The numerator becomes either positive or negative, depending on, for example, differences in MFN rates or imports across products. In addition, when preferential rates are not zero, the difference between the two measures emerges. ${ }^{6}$

\footnotetext{
${ }^{5}$ One may think that the sum of imports multiplied by preferential rates or applied tariff rates would also yield valuable information. However, these rates cannot be easily collected. In particular, the publicly available data on applied tariff rates do not take GSP rates into account.

${ }^{6}$ In order to more precisely analyze how MFN or preferential rates affect the difference between
} 
Another important issue concerns zero MFN rates. As it is clear from equation (1), including products with zero MFN rates in computing the preference utilization ratio increases imports under MFN rates in the denominator. It may also increase preferential imports particularly in the case of RTAs with cumulation rules because firms have incentive to import products under those RTA schemes even when tariff rates are zero (notice that preferential rates are also zero for products with zero MFN rates), in order to enjoy cumulation rules (see, for example, Hayakawa et al., 2013). On the other hand, as is evident from equations (2) and (3), the inclusion of such products does not affect tariff exemption ratio levels at all. Thus, the tariff exemption ratio should be interpreted as showing the extent of preference utilization only for imports of products with positive MFN rates. Therefore, when examining the time-series changes in tariff exemption ratios, we should take great care of possibly different sets of zero-MFN-rate products over time. ${ }^{7}$

For later use, the tariff exemption ratio $E$ multiplied by total imports of products with positive MFN rates is called exemption-basis preferential imports. The rest of imports of products with positive MFN rates are exemption-basis non-preferential imports. On the other hand, $I^{M}$ and $I^{P}$ are called utilization-basis non-preferential imports and utilization-basis preferential imports, respectively. Obviously, exemption-basis preferential imports are not necessarily consistent with utilization-basis preferential imports. While the former indicates the magnitude of preferential imports evaluated based on the magnitude of exempted tariff revenues, the latter's evaluation is based on whether or not preference schemes are utilized. Using these terms, we can say that our tariff exemption ratio is the share of exemption-basis preferential imports out of total imports of products with positive MFN rates, while the preferential utilization ratio is the share of utilization-basis preferential imports.

The tariff exemption ratio offers a remarkable advantage in practice. Calculating the preference utilization ratio obviously requires data on import values by tariff schemes. However, most countries do not disclose such data. On the other hand, we can compute the tariff exemption ratio by employing only publicly available data. The numerator in the second term in equation (2) is total government revenues from import duties. If we use the import-weighted average of (applied) MFN rates, the denominator

these two measures, it is necessary to take into account that $I_{i}^{M}$ and $I_{i}^{P}$ are functions of $t_{i}^{M}$ and $t_{i}^{P}$. Namely, we need to specify some theoretical model on firms' utilization of preferential schemes, as in Demidova and Krishna (2008).

${ }^{7}$ Also, imports of products in which preferential rates are equal to MFN rates but are positive do not affect the numerator in equation (3). However, since they do affect the denominator, the tariff exemption ratio should be interpreted as including the extent of preference utilization in such products. 
becomes the weighted average of MFN rates multiplied by total imports. As a result, equation (2) can be rewritten as follows: ${ }^{8}$

$$
E=1-\frac{\text { Total Revenues from Import Duties }}{(\text { Weighted Average of MFN Rates }) \times(\text { Total Imports })} .
$$

Computing the tariff exemption ratio requires only three sets of data: (1) the weighted average of MFN rates, (2) total revenues from import duties, and (3) total imports, all of which are available in public databases. Using the definition of tariff burden ratio, we may further simplify equation (5) as follows:

$$
E=1-\frac{\text { Tariff Burden Ratio }}{\text { Weighted Average of MFN Rates }} .
$$

There are three points to be noted in applying equation (5). First, as mentioned before, the tariff exemption ratio measures the extent of preference utilization for imports of products with positive MFN rates. However, we can still use data on total imports, not those on imports in products with positive MFN rates, as long as the weighted average of MFN rates among all products is used. Indeed, total imports multiplied by the weighted average of MFN rates do not change depending on whether or not information for products with zero MFN rates is included. Second, unlike the preference utilization ratio, the tariff exemption ratio cannot be calculated on a bilateral basis because data on government revenues from import duties are not available by trading partners. It may also be impossible to compute it using product-level data. Third, we cannot separately measure the utilization of individual preferential schemes including RTA schemes, GSP schemes, or various kinds of special trade arrangements (e.g., duty-drawback systems). Our tariff exemption ratio measures the utilization of the entire preferential scheme.

\section{Computation for Thailand}

This section calculates the tariff exemption ratio in Thailand. First, in order to check its performance in terms of similarity to the preference utilization ratio, we compute and compare these two measures. Next, we demonstrate that the computed tariff exemption ratio differs widely across data sources.

\subsection{Preference Utilization Ratio versus Tariff Exemption Ratio}

We examine the performance of the tariff exemption ratio by comparing it with the preference utilization ratio for Thailand since the data necessary for computing both

\footnotetext{
${ }^{8}$ For more details on the equivalence between equations (2) and (5), see Appendix A.
} 
are available for this country. Specifically, we employ the dataset obtained from customs in the Kingdom of Thailand. It contains transaction-level import data from 2007 to 2011 for all commodity imports in Thailand. ${ }^{9}$ Commodities are classified at a harmonized system (HS) eight-digit level. When computing the preference utilization ratio, we use the information on imports according to tariff schemes including MFN rates, RTA schemes, and other schemes, which include duty-free schemes such as investment promotions or duty drawbacks for re-exports. Thus, imports under the latter two kinds of schemes are classified as preferential imports.

When computing the tariff exemption ratio, we directly calculate actual revenues from import duties by employing the above-mentioned import data according to tariff schemes in addition to the data on tariff rates from customs. Namely, actual customs revenues are obtained by multiplying each type of imports by the corresponding tariff rates at a tariff line level and aggregating the resulting values. Hypothetical tariff revenues are computed by multiplying total imports by MFN rates at a tariff line level and aggregating the resulting values. Finally, we obtain the weighted average of MFN rates by dividing hypothetical tariff revenues by total imports. Such MFN rates are equivalent to weighted-average MFN rates computed using HS eight-digit-level imports and MFN rates.

The two ratios in Thailand are reported in Table 1. The upper panel shows values for all products including products with zero MFN rates. Columns (I)-(III) report import values according to three tariff schemes. Column (IV) shows their sum total. The figures in these four columns enable us to compute the preference utilization ratio, which is reported in column (VIII). It lies in a range of $38 \%$ to $44 \%$. The import-weighted average of MFN rates is shown in column (V). ${ }^{10}$ While the actual government revenues from import duties are reported in column (VI), the hypothetical tariff revenues from total imports are shown in column (VII). The resulting tariff exemption ratio is reported in column (IX), and it can be seen that it lies in a range of $49 \%$ to $58 \%$. We can see in the case of all products that the tariff exemption ratio is around 10 percentage points higher than the preference utilization ratio.

\section{$===$ Table 1 ===}

The case when products with zero MFN rates are excluded is shown in the lower

\footnotetext{
${ }^{9}$ The same data are used in Hayakawa et al. (2016).

${ }^{10}$ The rise of average MFN rates in Thailand over time is due to the change in imports, i.e., change of weight, rather than the rise in MFN rates.
} 
panel of Table 1. As mentioned in the previous section, the tariff exemption ratio and actual/hypothetical tariff revenues do not change. On the other hand, the import values for each tariff scheme decrease naturally. Also, the weighted average of MFN rates will increase, though we do not use it here. As a result, the preference utilization ratio rises to lie in a range of $45 \%$ to $56 \%$. Surprisingly, these preference utilization ratio levels are almost the same as those for the tariff exemption ratio. The difference between these two kinds of ratios is at most 4 percentage points. Except for the case of 2007, it is only 0 to 2 percentage points. Thus, at least in the case of Thailand, the tariff exemption ratio is almost equal to the preference utilization ratio.

\subsection{Sensitivity to Data Sources}

In the case of Thailand, we obtained customs data; using the complete set of disaggregated trade data can yield a clean and precise tariff exemption ratio. However, in applying this method to other countries, we have to depend on publicly available aggregated figures. In this subsection, we examine the extent to which differences in data sources affect the estimated values of tariff exemption ratios.

The results are reported in Table 2. For comparison, we provide figures in "All Products" and "Positive MFN Products" from Table 1 in cases (i) and (ii), respectively. In case (iii), we compute the tariff exemption ratio for Thailand by employing the data derived only from the WDI. ${ }^{11}$ Specifically, we obtain data on "Customs and other import duties." "Goods imports,” and "Tariff rate, most favored nation, weighted mean, all products.” The original source for the data on customs and other import duties is the Government Finance Statistics (GFS) from the International Monetary Fund (IMF). The original sources for imports and MFN rates are International Financial Statistics (IFS) from the IMF and the World Integrated Trade Solution (WITS) database, ${ }^{13}$ respectively. In case (iv), we employ import data obtained from UN Comtrade and WDI data for MFN rates and tariff revenues.

\section{$===\quad$ Table 2 ===}

\footnotetext{
${ }^{11}$ In this table, we restrict the sample years only to 2007-2009 as the data for Thailand in the WDI are not available for 2010 and 2011.

12 The WDI metadata refers that "Customs and other import duties are all levies collected on goods that are entering the country or services delivered by nonresidents to residents. They include levies imposed for revenue or protection purposes and determined on a specific or ad valorem basis as long as they are restricted to imported goods or services."

${ }^{13}$ However, as mentioned later, MFN rates reported in WDI are quantitatively different from those reported in WITS.
} 
Since the WDI/Comtrade data are based on those for all products, we should compare figures for imports, MFN rates, and tariff revenues in cases (iii) and (iv) with those in case (i). Compared with figures derived from the customs data, the values of imports are larger in Comtrade and smaller in the WDI (i.e., IFS). Various reasons can underlie such differences in total imports. For example, according to the IMF website, figures for total imports are not necessarily the same between IFS and UN Comtrade since these are based on different data collection systems with different aims, procedures, timetables, and sources for updates and maintenance. These differences result in gaps in total imports across data sources.

The weighted average of MFN rates is slightly higher in the WDI (i.e., WITS). The main source of this variation may be a difference in aggregation level. According to the WDI metadata, tariff rates and the imports used for weight in its data are first separately aggregated to a standard international trade classification (SITC) five-digit level. Then, the weighted average of MFN rates is computed. On the other hand, as mentioned above, our MFN rates are computed by employing HS eight-digit-level data of imports and MFN rates. Differences may additionally arise due to the fact that we employ tariff-equivalent rates for specific rates in the case of customs data, though it is unclear whether or not the WDI data also employ the same rates.

Revenues from import duties are smaller in the WDI (i.e., GFS). As mentioned in the next section, there are several kinds of limitation in revenue data. In addition, when we directly compute tariff revenues by multiplying imports by MFN rates, our use of tariff-equivalent rates for specific duties may lead to the gap seen in the case of the WDI data. Another issue is that the original source of WDI data for both imports and tariff revenues is IMF estimates. Thus, in the case of WDI data, lower tariff revenue values are consistent with those of imports. In other words, other things being equal, lower levels of imports automatically lead to lower tariff revenues. In this sense, as shown below, the gap in imports and tariff revenues between WDI and customs data may not yield a large difference in the tariff exemption ratio between those two sources.

As mentioned in the previous subsection, the tariff exemption ratio should be interpreted as showing the extent of preference utilization in imports only for products with positive MFN rates. Thus, the tariff exemption ratio computed using WDI/Comtrade data should be compared with the preference utilization ratio and tariff exemption ratio in case (ii). The tariff exemption ratio in case (iii) is around 10 percentage points higher than the preference utilization ratio and the tariff exemption ratio in case (ii). The ratio in case (iv) is around 15 percentage points higher. Thus, the tariff exemption ratio based on WDI/Comtrade data overestimates the extent of 
preference utilization. In other words, the tariff exemption ratio level depends upon the data sources used in its computation. Furthermore, as mentioned above, the lesser degree of overestimation in case (iii) may be due to the use of WDI data for imports and tariff revenues, both of which are IMF estimates. Thus, we should avoid a mix of data sources when computing the tariff exemption ratio.

\section{Tariff Exemption Ratios around the World}

This section presents the tariff exemption ratio for most countries. First, we introduce the ratio computed by employing only data from well-known databases. Next, to improve its accuracy, we compute it by employing another data source of the weighted average of MFN rates.

\subsection{Use of the WDI Database}

In this subsection, we employ two databases to compute tariff exemption ratios. One is the WDI. The specific variables obtained from the WDI are the same as those used for the case of Thailand in the previous subsection: "Customs and other import duties," "Goods imports," and "Tariff rate, most favored nation, weighted mean, all products." The other data are taken from the OECD iLibrary. Despite our earlier caveat about mixing data sources, the absence of data on customs and other import duties for most European countries in the WDI means we must employ another publicly available database, OECD iLibrary. We employ data on customs and other import duties in the OECD iLibrary for all OECD countries. Specifically, we use data on "5123 Customs and import duties" and "Custom duties collected for the EU" in the Revenue Statistics from OECD Tax Statistics. Since we employ the latest data available in each country, the sample year differs by country.

There are some shortcomings in the data on customs and other import duties. First, while many countries report customs duties by fiscal year, other data, such as import data, are reported by calendar year. In this sense, some gaps in values will exist between these data. Second, if the duty paid in a year is refunded in the next year, the tariff exemption ratio does not necessarily indicate the use of preference in that year. Third, some countries do not consolidate central and local government finance data into one account and present only central government budgetary accounts. In the case of customs and other import duties, even central government budgetary accounts will show the whole picture, but we will address this issue later. Due to these various sources of noise, the tariff exemption ratio becomes too large or negative for a few countries. We exclude 
countries with such ratios (i.e., greater than 1.05 or negative). As a result, 12 countries are excluded. We set 1 if the ratio lies in the range of 1 to 1.05 .

We compute the tariff exemption ratio for 112 countries. The ratio for each country is shown in column "WDI" in Table $3 .{ }^{14}$ We report sample year, tariff exemption ratio, and the weighted average of MFN rates. Countries with ratio values of one are small countries in the EU. If those countries import goods only from other EU members, the tariff exemption ratio may take the value of one. However, such a case would be rare. Rather, ratios with a value of one would arise because of the above-mentioned minor errors in tariff revenues. In any case, those countries do have tariff exemption ratios close to the value of one. On the other hand, countries with zero ratios are small island countries. In contrast to the cases with a ratio of one, zero ratios are likely to exist. For example, some countries may not offer any preferential schemes to exporters. In this case, the tariff exemption ratio is always zero. ${ }^{15}$

\section{$===$ Table 3 ===}

The basic statistics for global tariff exemption ratios are provided in Table 4. The sample mean is 0.54 while the standard deviation is $0.32 .{ }^{16}$ In the table, ratios are also shown by region. In terms of simple means, Europe has the highest ratio, followed by East or Southeast Asia and North America. In the 2000s, ASEAN members formed regional agreements with major trading partners, i.e., Australia, China, India, Japan, Korea, and New Zealand. Korea also actively conducts RTAs with its major trading partners including not only Asian countries but also the U.S. and European countries. These active RTA formations lead to high tariff exemption ratios in East or Southeast Asia. On the other hand, Africa, South or West Asia, and the countries in the Pacific

\footnotetext{
14 The kernel density of the tariff exemption ratio is shown in Figure B1.

${ }^{15}$ Using figures for the preference utilization ratio in Keck and Lendle (2012), we can check the differences between our tariff exemption ratio and the preference utilization ratio in various countries. Specifically, Table 1 in Keck and Lendle (2012) showed import values according to tariff schemes (i.e., MFN, RTA, and GSP) and MFN rates (i.e., zero or positive) in Australia, Canada, and the US (and EU) in 2008. The preference utilization ratio for products with positive MFN rates is $18 \%$ in Australia, 70\% in Canada, and 55\% in the US. On the other hand, tariff exemption ratios in 2008 were 20\% in Australia, 75\% in Canada, and 56\% in the US. Therefore, the difference between the two measures is surprisingly small in these countries.

${ }^{16}$ In order to minimize errors from the use of data in specific years, we also compute tariff exemption ratios by employing the latest three-year average of each variable. Since the data are available for only one or two years in some countries, the number of countries for which we can compute the ratio is reduced to 71 . We also compute statistics for the same set of countries employing data from the latest single year. As a result, the mean values are almost identical between these two cases ( 0.59 for a three-year average or 0.58 for a single year), though the case of the three-year average (0.32) shows a smaller standard deviation than the case of a single year (0.34).
} 
have relatively small means of tariff exemption ratios. In these regions, preference schemes are not widely utilized in trading. In particular, among Pacific countries, Australia and Vanuatu have low ratios whereas New Zealand has a relatively high ratio.

\section{$===$ Table 4 ===}

The lower panel of Table 4 reports the basic statistics by major RTAs, including the ASEAN Free Trade Area (AFTA), the Common Market for Eastern and Southern Africa (COMESA), the EU, Mercado Común del Sur (MERCOSUR), the South Asian Free Trade Area (SAFTA), and the North American Free Trade Agreement (NAFTA). ${ }^{17}$ We identify member countries as of 2014, though the sample years in some countries may be taken from years before they joined RTAs. Statistics in an RTA do not show those in imports among members of that RTA but present those in their total imports. From this panel, we can see that the EU has the highest mean tariff exemption ratios (96\%), followed by AFTA and NAFTA, whose mean ratios are each around 65\%. As Table 1 shows (i.e., the case of Thailand), the utilization of not only RTA schemes but also other tariff exemption schemes such as duty drawbacks for re-exports leads to high ratios in AFTA. COMESA, MERCOSUR, and SAFTA have mean tariff exemption ratios of approximately $40 \%$.

\subsection{Use of the WITS Database}

In the previous section, we discussed how the weighted average of MFN rates affects tariff exemption ratio estimates. In particular, WDI data are computed by aggregating import and tariff data at an SITC five-digit level. We can improve this data by employing WITS data, ${ }^{18}$ which provides data aggregated using each country's tariff line-level data. ${ }^{19}$ However, countries for which data are available in the WITS are limited compared to those in the WDI. As a result, we here compute the tariff exemption ratio for 83 countries. The results are shown in the column "WITS" in Table 3. Again, we report sample year, tariff exemption ratio, and weighted average of MFN rates. We

\footnotetext{
${ }^{17}$ The EU comprises Austria, Bulgaria, Cyprus, Croatia, Czech Republic, Finland, France, Greece, Hungary, Ireland, Latvia, Luxembourg, Malta, Poland, Portugal, Romania, Slovak Republic, Slovenia, Spain, Sweden, and United Kingdom. MERCOSUR includes Brazil, Paraguay, Uruguay, and Venezuela. AFTA includes Cambodia, Indonesia, Lao PDR, Malaysia, Singapore, and Thailand. NAFTA includes Canada, Mexico, and the US. COMESA includes Democratic Republic of Congo, Egypt, Arab Rep., Kenya, Mauritius, Rwanda, Seychelles, Uganda, and Zambia. SAFTA includes Afghanistan, Bangladesh, Bhutan, India, Maldives, Nepal, Pakistan, and Sri Lanka.

18 This database is also publicly and freely available after registration.

19 As mentioned in the previous section, the original source of tariff data in the WDI is also WITS, but WDI data are constructed by aggregation at an SITC five-digit level.
} 
can see cases of both overestimation and underestimation on the weighted average of MFN rates and thus on tariff exemption ratios. On average, the difference in tariff exemption ratios between the WDI and WITS cases is just $3 \%{ }^{20}$

Using this improved measure, we also examine time-series changes in tariff exemption ratios. The ratios for selected countries during the period 2005-2012 are shown in Figure 1. These countries are selected based not only on their data availability ${ }^{21}$ but also in consideration of the significance of the size of their economies, geographical diversity, and prevalence of RTAs. Also, except for South Africa, these countries do not show significant changes in their share of products with zero MFN rates. ${ }^{22}$ Remember that our tariff exemption ratios measure the preference utilization in products with positive MFN rates. Therefore, the time-series changes of tariff exemption ratios in these countries can be seen as those of preference utilization rather than those of a set of products with positive MFN rates. ${ }^{23}$ As for other countries, for example, countries with tariff exemption ratios equal to or near the value of one in Table 3, i.e., European countries, have similar levels for other years as well.

\section{$===$ Figure $1 \quad===$}

The figure shows various interesting changes. The tariff exemption ratio in the US changes over time in a range of 0.3 to 0.5 . Its decrease may be due to unilateral liberalization. In the US, the weighted average of MFN rates (obtained from the WITS) drops from $2.7 \%$ in 2005 to $2.1 \%$ in 2012. Such a reduction decreases the preference margin, resulting in firms in RTA partner countries being discouraged from utilizing RTA schemes when exporting to the US. While tariff exemption ratios in Chile and Norway are rising, those in China and Brazil are gradually decreasing. In particular, the rise in Chile's ratio is significant and is consistent with the fact that Chile is actively

\footnotetext{
${ }^{20}$ Further basic statistics on the difference in tariff exemption ratios between cases of WDI and WITS are available in Table B1 in Appendix B.

${ }^{21}$ In particular, the WDI database provides data on imports only since 2005. Thus, if we employ other data sources such as UN Comtrade, we can extend the sample years. For some countries, we can compute the tariff exemption ratio up to 1988, as data on the weighted average of MFN rates have been available in the WDI since that time. In this paper, to maintain consistency of data sources with other tables and figures, we do not mix data sources on imports to determine values for such a longer period but instead show those since 2005.

${ }^{22}$ Table B2 in Appendix B reports the share of products with zero MFN rates in these countries.

${ }^{23}$ In addition, tariff exemption ratios are likely to change from 2006 to 2007 or from 2011 to 2012 due to a change in HS versions, i.e., from HS2002 to HS2007 or from HS2007 to HS2012. In general, the changes of tariff line structures affect aggregated values of the MFN rates. Thus, a change in weighted averages of MFN rates through a change of HS versions will affect tariff exemption ratios.
} 
increasing the number of RTA partners during the sample period. One of the reasons for China's decrease may be due to a decline in the processing trade, which is one type of preferential trade, during the financial crisis (Yu and Tian, 2012). In the cases of Australia and Japan, the ratios remain low. South Africa's ratio is unstable partly because of changes in the share of products with zero MFN rates. Such a change significantly affects tariff exemption ratio values. In addition, we may doubt the accuracy of South Africa's data on tariff revenues.

Next, we conduct quasi-decomposition of total imports. Specifically, we decompose total imports into three types. The WITS database provides data on the share of imports of zero-MFN-rate products, i.e., duty-free imports, in total imports. We name this share "Free.” Multiplying "one minus Free" by the tariff exemption ratio, we obtain the share of exemption-basis preferential imports to total imports, as defined in Section 2. We name this share "Exempted." As a result, one minus "Free plus Exempted" indicates the share of exemption-basis non-preferential imports out of total imports, named "Non-exempted.” Importantly, as discussed so far, Exempted is not precisely the same as the share of actual preferential imports (i.e., utilization-basis preferential imports) out of total imports. Nevertheless, this decomposition of total imports offers invaluable information.

The results are shown in Figure 2. For reference, we also show the share of the tariff line-level products with zero MFN rates in total, data for which are obtained from the WITS. This figure tells that, for example, in the US, $40 \%$ of total imports are duty-free imports, $20 \%$ are exemption-basis preferential imports, and $40 \%$ are exemption-basis non-preferential imports. It also shows that, in Norway, while the tariff exemption ratio (WITS) is around 50\% as reported in Table 3, 90\% of total imports are already imported duty free. In contrast, most imports in Chile are exemption-basis preferential imports. The magnitude of duty-free imports in Chile is trivial. In short, this figure is useful for learning the composition of various types of imports in terms of tariff schemes.

\section{$==$ Figure $2 \quad===$}

\section{Correlation with Various Elements}

This section examines the correlation of tariff exemption ratios with a number of elements. For this analysis, we use the tariff exemption ratios in column "WDI" in Table 
3 in order to capture a wider variation among a larger number of countries. ${ }^{24}$ We try several kinds of variables, for which the basic statistics are listed in Table 5.

\section{$===$ Table 5 ===}

\subsection{Basic Elements}

We first regress tariff exemption ratios on the share of imports from RTA member countries in total imports (Preference share: RTA) by ordinary least squares (OLS). ${ }^{25,26}$ It is natural that, ceteris paribus, the higher the share of imports from RTA members, the higher the tariff exemption ratio. Information on RTA membership is obtained from the regional trade agreement database on the WTO website. Bilateral trade data are from UN Comtrade. The result, reported in column (I) in Table 6, shows a significantly positive coefficient for this variable. The magnitude of this coefficient, i.e., 0.756, might be interpreted as indicating global average rates of RTA utilization when importation under RTA schemes is possible. ${ }^{27}$

\section{$===$ Table $6 \quad===$}

Second, we add export intensity, defined as the ratio of total exports to GDP, into the estimation equation. As in the above case of Thailand, some countries, particularly developing countries, refund import duties for imports used to produce products for export. Thus, it is natural that countries actively engaged in such trade have higher tariff exemption ratios. However, since it is empirically difficult to precisely measure the extent of such trade, we use the export intensity as a proxy. The result is reported in column (II). The coefficients for both Preference share and Export intensity are

\footnotetext{
${ }^{24}$ The estimation results using tariff exemption ratios in column "WITS" are reported in Table B3 in Appendix B.

${ }^{25}$ For simplicity in interpreting marginal effects, we report only OLS results. However, the statistical significance of coefficients in all estimations are not changed even if we estimate all models by the fractional logit model, which is a more suitable estimation technique for models in which the dependent variable lies at unit intervals $[0,1]$. The results are reported in Table B3 in Appendix B.

${ }^{26}$ Obviously, RTA schemes cannot necessarily be applied to all products, even when trading among RTA member countries. However, for simplicity in computation, we use total imports from RTA member countries as the numerator. In addition, for simplicity, imports in both the numerator and denominator include those of products with zero MFN rates although the dependent variable, i.e., the tariff exemption ratio, does not include the extent of preference utilization for such products.

${ }^{27}$ This magnitude looks reasonable. Table 8 in Keck and Lendle (2012) reported the preference utilization ratio by importers (Australia, Canada, EU, or the US) and preferential schemes (RTA or GSP). Most cases show preference utilization ratios of more than $80 \%$, although this restricts sample products only to those with preference rates lower than MFN rates.
} 
estimated to be significantly positive. The magnitude of the former coefficient falls slightly to 0.693 . The latter result indicates that the tariff exemption ratio is higher in export-intensive countries.

Third, as in the case of RTAs, we introduce the share of imports from GSP beneficiaries out of total imports (Preference share: GSP). ${ }^{28}$ GSP beneficiary information is obtained from the preferential trade agreement database on the WTO website. The results are reported in columns (III) and (IV). The coefficients for both preference share from RTA members and export intensity are again estimated to be significantly positive. The magnitude of the former's coefficient is further reduced. Coefficients for the preference share from GSP beneficiaries are estimated to be positively significant. Its coefficient may again be interpreted as indicating global average GSP utilization rates, which are more than $90 \%{ }^{29}$

\subsection{Advanced Elements}

We further examine the correlation with tariff exemption ratios. Following the literature on the determinants of RTA utilization rates, studies on which are listed in the introductory section, we first examine the role of preference margin, i.e., the difference between preference and MFN rates. It is well known that RTA schemes are more likely to be utilized when preference margins are larger. As a proxy for this variable, we work with a difference between simple averages of applied tariff rates and MFN rates. Data on both types of tariff rate are obtained from the WDI. Since the former kind of tariff data in the WDI is based on both MFN rates and RTA rates, this variable will be strongly related to preference margins. ${ }^{30}$ The results are shown in column (I) in Table 7. Consistent with the above expectation, we find a positively significant coefficient for this new variable. Specifically, a 1 percentage point larger preference margin leads to a 2.6 percentage point larger tariff exemption ratio.

\section{$===$ Table 7 ===}

Second, we also examine the correlation of economic development by introducing GDP per capita. The results are shown in column (II) in Table 7. The coefficient for preference margin is again estimated to be significantly positive, whereas the coefficient

\footnotetext{
${ }^{28}$ As in the case of RTAs, we use import data for all products. Also see footnote 26.

${ }^{29}$ As shown in Table 8 in Keck and Lendle (2012), the preference utilization ratio of GSP when importing from its beneficiaries is consistently high in Australia, Canada, the EU, and the US Several cases show preference utilization ratios higher than $90 \%$.

${ }^{30}$ However, data on applied tariff rates do not take other preferential rates into account.
} 
for GDP per capita is insignificant. The latter result implies that the tariff exemption ratio is not necessarily correlated with development stages. Several possible explanations can be offered for this insignificant result. On the one hand, GSP schemes are generally available when exporting to developed countries. This unilateral preference scheme will raise tariff exemption ratios in developed countries. On the other hand, tariff exemption schemes other than RTAs and the GSP, such as investment promotion or duty drawbacks for re-exports, are likely to be introduced in developing countries in order to attract more foreign investment or obtain larger amounts of foreign currency. As a result, these two opposite forces may produce an insignificant result in GDP per capita.

\subsection{Additional Controls}

Last, we again examine the correlation with the above elements when controlling for noise in tariff exemption ratios. As found in equation (4), variation in MFN rates and imports across products leads to a gap between the tariff exemption ratio and the preferential utilization ratio. Thus, we introduce the following two variables to control for such differences. One is a difference between the weighted average of MFN rates and the simple average of MFN rates (Weighted-Simple MFN difference), which can proxy for variations in imports across products. The other is the share of products with MFN rates greater than $15 \%$ (Share of high MFN products), which is partly related to differences in MFN rates across products. Furthermore, we introduce shares of products with specific MFN rates (Share of specific tariff products). As mentioned above, the existence of specific rates affects the degree of precision in weighted-average MFN rates and thus in tariff exemption ratios. All three variables are derived from the WDI.

We introduce additional elements. In the previous section, we pointed out the role of unilateral trade liberalization in time-series changes in tariff exemption ratios. Although our exercise in this section is a cross-country and not a time-series analysis, the unilateral trade liberalization may also affect the absolute magnitude of tariff exemption ratios. To control for this effect, we introduce the share of products with zero MFN rates (Share of zero MFN products), data for which are obtained from UNCTAD. Unfortunately, due to data limitations, such a share can only be computed for manufactured goods, ores, and metals (SITC (Rev. 3): $5+6+7+8+27+28-667$ ). ${ }^{31}$

\footnotetext{
${ }^{31}$ Data on this variable are missing for Japan and Israel for the corresponding year in the tariff exemption ratio (2012). Thus, we use the share of zero MFN products in 2011 for Japan and in 2009 for Israel. In addition, when we restrict sample countries to those for whom WITS data are available, namely, when we examine tariff exemption ratios in the column "WITS" in Table 3, we can use the data on Share of zero MFN products in all goods including agricultural goods, as shown in Figure 2.
} 
We also introduce a dummy variable taking the value of one if government finance data in a country are consolidated into one account, and zero otherwise (Consolidated dummy). The information for this variable can be derived from the WDI metadata.

The results are reported in column (III). The results in the previous variables are qualitatively unchanged. Namely, except for GDP per capita, preference shares of RTA and GSP, export intensity, and preference margin have positively significant coefficients. In particular, the 1 percentage point larger preference margin leads to a 4.7 percentage point larger ratio of tariff exemptions. Coefficients for the weighted-simple MFN difference and share of high MFN products are estimated to be significantly positive, indicating that variations of import and MFN rates across products have a systematic influence on tariff exemption ratios. On the other hand, the share of specific tariff products, share of products with zero MFN rates, and the consolidated dummy have insignificant coefficients and thus do not affect the cross-country differences in our tariff exemption ratio. ${ }^{32}$

\section{Concluding Remarks}

In this study, we proposed a new indicator that measures the extent of preference utilization. In contrast to the measure usually employed, i.e., the preference utilization ratio, our new measure, called the tariff exemption ratio, can be computed by employing only publicly available databases such as the WDI database. First, we used detailed data on Thailand to demonstrate that our measure is a very good indicator for measuring the extent of preference utilization for trade in products with positive MFN rates. Second, we demonstrated that computed tariff exemption ratios differed widely across data sources. Third, by computing our measure for a large number of countries, we found that the tariff exemption ratio differed widely across countries and that its global average was approximately 50\%. Finally, we also showed that it was positively associated with the magnitude of preference margin.

The tariff exemption ratio can serve as a strong policy measure. Until now, one policy measure on RTAs was the share of imports from RTA partners out of total

The results are reported in Table B3 in Appendix B.

${ }^{32}$ As reported in Table B3 in Appendix B, the results for our main variables are qualitatively unchanged even when employing the fractional logit model. However, these are changed when estimating the tariff exemption ratios in "WITS" in Table 3. Specifically, the coefficients for "Preference share: GSP," "Export intensity," and "Share of high MFN products" turn out to be insignificant. Those for "Share of specific tariff products" and "Share of zero MFN products" become significantly positive and negative, respectively. However, the results for "Preferential share: RTA" and "Preference margin," which are our main variables, are not changed. 
imports, which does not necessarily reflect the utilization of preferential schemes. However, it is highly important to exploit RTA schemes and thus to enhance the utilization of preferential schemes. In addition, it may be effective to encourage RTA partner countries to facilitate imports under RTA schemes if they have low utilization of preferential schemes. To uncover such utilization, we need detailed and specific information. Some countries may not have such data readily available, even for their own countries. They definitely do not know the utilization of preferential schemes in other countries unless such data are disclosed. Against this backdrop, the method proposed here for computing tariff exemption ratios requires only publicly available data and is technically easy. It is expected that through monitoring the tariff exemption ratio in each country, utilization preferences can be enhanced worldwide. 


\section{References}

Agbeyegbe, T., Stotsky, J.G., and Woldemariam, A., 2006, Trade Liberalization, Exchange Rate Changes, and Tax Revenue in Sub-Saharan Africa, Journal of Asian Economics, 17: 261-284.

Baunsgaard, T. and Keen, M., 2010, Tax Revenue and (or?) Trade Liberalization, Journal of Public Economics, 94: 563-577.

Bureau, J., Chakir, R., and Gallezot, J., 2007, The Utilisation of Trade Preferences for Developing Countries in the Agri-food Sector, Journal of Agricultural Economics, 58(2): 175-198.

Cadot, O., Carrere, C., De Melo, J., and Tumurchudur, B., 2006, Product-specific Rules of Origin in EU and US Preferential Trading Arrangements: An Assessment, World Trade Review, 5(2): 199-224.

Demidova, S. and Krishna, K., 2008, Firm Heterogeneity and Firm Behavior with Conditional Policies, Economics Letters, 98(2): 122-128.

Francois, J., Hoekman, B., and Manchin, M., 2006, Preference Erosion and Multilateral Trade Liberalization, World Bank Economic Review, 20(2): 197-216.

Hakobyan, S., 2015, Accounting for Underutilization of Trade Preference Programs: U.S. Generalized System of Preferences, Canadian Journal of Economics, 48(2), 408-436.

Hayakawa, K., 2014, Impact of Diagonal Cumulation Rule on FTA Utilization: Evidence from Bilateral and Multilateral FTAs between Japan and Thailand, Journal of the Japanese and International Economies, 32: 1-16.

Hayakawa, K., Kim, H., and Lee, H., 2014, Determinants on Utilization of the Korea-ASEAN Free Trade Agreement: Margin Effect, Scale Effect, and ROO Effect, World Trade Review, 13(3): 499-515.

Hayakawa, K., Laksanapanyakul, N., and Shiino, K., 2013, Some Practical Guidance for the Computation of Free Trade Agreement Utilization Rates, IDE Discussion Papers 438.

Hayakawa, K., Laksanapanyakul, N., and Urata, S., 2016, Measuring the Costs of FTA Utilization: Evidence from Transaction-level Import Data of Thailand, Forthcoming in the Review of World Economics.

Hisali, E., 2012, Trade Policy Reform and International Trade Tax Revenue in Uganda, Economic Modelling, 29: 2144-2154.

Khattry, B. and Mohan, J.R., 2002, Fiscal Faux Pas?: An Analysis of the Revenue Implications of Trade Liberalization, World Development, 30(8): 1431-1444. 
Keck, A. and Lendle, A., 2012, New Evidence on Preference Utilization, World Trade Organization, Staff Working Paper ERSD-2012-12.

Manchin, M., 2006, Preference Utilisation and Tariff Reduction in EU Imports from ACP Countries, The World Economy, 29(9): 1243-1266.

Yu, M. and Tian, W., 2012, China’s Processing Trade: A Firm-Level Analysis, In: Huw McMay and Ligang Song (eds.) Rebalancing and Sustaining Growth in China, Australian National University E-press, 111-148. 
Table 1. Preference Utilization Ratios versus Tariff Exemption Ratios: Case of Thailand (Billion THB)

\begin{tabular}{|c|c|c|c|c|c|c|c|c|c|}
\hline & (I) & (II) & (III) & (IV) & \multirow{3}{*}{$\begin{array}{c}(\mathrm{V}) \\
\text { MFN rates }\end{array}$} & (VI) & (VII) & \multirow{3}{*}{$\begin{array}{c}\text { (VIII) } \\
\mathrm{V} \\
((\mathrm{I})+(\mathrm{III})) /(\mathrm{IV})\end{array}$} & \multirow{3}{*}{$\begin{array}{c}\text { (IX) } \\
\mathrm{E} \\
1-((\mathrm{VI}) /(\mathrm{VII}))\end{array}$} \\
\hline & \multicolumn{4}{|c|}{ Imports } & & \multicolumn{2}{|c|}{ Tariff Revenues } & & \\
\hline & RTA & MFN & Others & $\begin{array}{c}\text { Total } \\
\text { (I)+(II)+(III) }\end{array}$ & & Actual & $\begin{array}{l}\text { Hypoth. } \\
(\mathrm{IV}) *(\mathrm{~V})\end{array}$ & & \\
\hline \multicolumn{10}{|l|}{ All Products } \\
\hline 2007 & 9 & 2,981 & 1,832 & 4,822 & 0.041 & 101 & 197 & 0.38 & 0.49 \\
\hline 2008 & 119 & 3,252 & 2,395 & 5,767 & 0.040 & 114 & 230 & 0.44 & 0.50 \\
\hline 2009 & 153 & 2,695 & 1,582 & 4,431 & 0.045 & 99 & 200 & 0.39 & 0.50 \\
\hline 2010 & 339 & 3,448 & 1,914 & 5,701 & 0.048 & 129 & 272 & 0.40 & 0.52 \\
\hline 2011 & 659 & 3,828 & 2,117 & 6,604 & 0.047 & 130 & 307 & 0.42 & 0.58 \\
\hline \multicolumn{10}{|c|}{ Positive MFN Products } \\
\hline 2007 & 6 & 1,312 & 1,063 & 2,381 & 0.083 & 101 & 197 & 0.45 & 0.49 \\
\hline 2008 & 117 & 1,426 & 1,230 & 2,773 & 0.083 & 114 & 230 & 0.49 & 0.50 \\
\hline 2009 & 150 & 1,146 & 966 & 2,262 & 0.089 & 99 & 200 & 0.49 & 0.50 \\
\hline 2010 & 323 & 1,433 & 1,205 & 2,961 & 0.092 & 129 & 272 & 0.52 & 0.52 \\
\hline 2011 & 615 & 1,464 & 1,238 & 3,317 & 0.093 & 130 & 307 & 0.56 & 0.58 \\
\hline
\end{tabular}

Source: Authors' computation 
Table 2. Sensitivity to Data Sources

\begin{tabular}{|c|c|c|c|c|c|c|}
\hline & \multirow{3}{*}{$\begin{array}{c}\text { (I) } \\
\text { Imports }\end{array}$} & \multirow{3}{*}{$\begin{array}{c}\text { (II) } \\
\text { MFN rates }\end{array}$} & (III) & (IV) & \multirow{3}{*}{$\begin{array}{l}\text { (V) } \\
\mathrm{V}\end{array}$} & \multirow{3}{*}{$\begin{array}{c}(\mathrm{VI}) \\
\mathrm{E} \\
1-((\mathrm{III}) /(\mathrm{IV}))\end{array}$} \\
\hline & & & \multicolumn{2}{|c|}{ Tariff Revenues } & & \\
\hline & & & Actual & $\begin{array}{l}\text { Hypoth. } \\
(\mathrm{I}) *(\mathrm{II})\end{array}$ & & \\
\hline \multicolumn{7}{|c|}{ 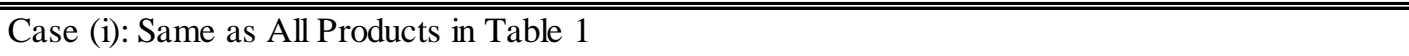 } \\
\hline Data source & Customs & Customs & Customs & & & \\
\hline 2007 & 4,822 & 0.041 & 101 & 197 & 0.38 & 0.49 \\
\hline 2008 & 5,767 & 0.040 & 114 & 230 & 0.44 & 0.50 \\
\hline 2009 & 4,431 & 0.045 & 99 & 200 & 0.39 & 0.50 \\
\hline \multicolumn{7}{|c|}{ Case (ii): Same as Positive MFN Products in Table 1} \\
\hline Data source & Customs & Customs & Customs & & & \\
\hline 2007 & 2,381 & 0.083 & 101 & 197 & 0.45 & 0.49 \\
\hline 2008 & 2,773 & 0.083 & 114 & 230 & 0.49 & 0.50 \\
\hline 2009 & 2,262 & 0.089 & 99 & 200 & 0.49 & 0.50 \\
\hline \multicolumn{7}{|l|}{ Case (iii) } \\
\hline Data source & WDI & WDI & WDI & & & \\
\hline 2007 & 4,487 & 0.044 & 87 & 198 & & 0.56 \\
\hline 2008 & 5,330 & 0.043 & 96 & 230 & & 0.58 \\
\hline 2009 & 4,114 & 0.049 & 76 & 202 & & 0.62 \\
\hline \multicolumn{7}{|l|}{ Case (iv) } \\
\hline Data source & Comtrade & WDI & WDI & & & \\
\hline 2007 & 4,962 & 0.044 & 87 & 219 & & 0.60 \\
\hline 2008 & 5,950 & 0.043 & 96 & 257 & & 0.63 \\
\hline 2009 & 4,586 & 0.049 & 76 & 226 & & 0.66 \\
\hline
\end{tabular}

Source: Authors’ computation 
Table 3. Global Tariff Exemption Ratios

\begin{tabular}{|c|c|c|c|c|c|c|}
\hline & \multicolumn{3}{|c|}{ WDI } & \multicolumn{3}{|c|}{ WITS } \\
\hline & Year & Ratio & Tariffs & Year & Ratio & Tariffs \\
\hline Afghanistan & 2012 & 0.12 & 6.8 & & & \\
\hline Algeria & 2009 & 0.48 & 11.3 & & & \\
\hline Angola & 2009 & 0.00 & 7.4 & & & \\
\hline Antigua and Barbuda & 2009 & 0.58 & 14.6 & 2009 & 0.48 & 11.7 \\
\hline Armenia & 2012 & 0.03 & 3.0 & 2012 & 0.12 & 3.4 \\
\hline Australia & 2011 & 0.04 & 2.5 & 2011 & 0.01 & 2.4 \\
\hline Austria & 2012 & 1.00 & 2.2 & 2012 & 1.00 & 2.4 \\
\hline Azerbaijan & 2012 & 0.53 & 6.2 & & & \\
\hline Bahamas, The & 2011 & 0.34 & 18.9 & & & \\
\hline Bahrain & 2011 & 0.67 & 6.9 & 2011 & 0.56 & 5.1 \\
\hline Bangladesh & 2006 & 0.30 & 19.9 & & & \\
\hline Barbados & 2007 & 0.67 & 19.2 & 2007 & 0.64 & 18.0 \\
\hline Belarus & 2012 & 0.28 & 4.9 & & & \\
\hline Benin & 2011 & 0.00 & 15.2 & & & \\
\hline Bhutan & 2007 & 0.96 & 17.8 & & & \\
\hline Bosnia and Herzegovina & 2009 & 1.00 & 8.8 & & & \\
\hline Brazil & 2012 & 0.30 & 10.2 & 2012 & 0.29 & 10.0 \\
\hline Bulgaria & 2012 & 0.97 & 2.2 & & & \\
\hline Burkina Faso & 2008 & 0.00 & 10.4 & 2008 & 0.00 & 10.5 \\
\hline Cambodia & 2008 & 0.55 & 11.4 & 2008 & 0.55 & 11.4 \\
\hline Canada & 2012 & 0.64 & 2.3 & 2012 & 0.63 & 2.2 \\
\hline Chile & 2010 & 0.84 & 6.0 & 2010 & 0.84 & 6.0 \\
\hline China & 2011 & 0.44 & 4.6 & 2011 & 0.39 & 4.2 \\
\hline Colombia & 2012 & 0.43 & 7.7 & 2012 & 0.54 & 9.5 \\
\hline Congo, Dem. Rep. & 2009 & 0.03 & 11.0 & & & \\
\hline Congo, Rep. & 2007 & 0.78 & 14.7 & & & \\
\hline Costa Rica & 2010 & 0.40 & 4.3 & 2010 & 0.34 & 3.9 \\
\hline Croatia & 2012 & 0.66 & 4.3 & 2012 & 0.65 & 4.3 \\
\hline Cyprus & 2012 & 0.78 & 2.2 & & & \\
\hline Czech Republic & 2012 & 1.00 & 2.2 & 2012 & 1.00 & 2.4 \\
\hline Dominica & 2011 & 0.28 & 13.9 & 2007 & 0.25 & 13.0 \\
\hline Dominican Republic & 2010 & 0.40 & 6.7 & 2010 & 0.39 & 6.6 \\
\hline Egypt, Arab Rep. & 2009 & 0.30 & 8.7 & 2009 & 0.35 & 9.4 \\
\hline El Salvador & 2012 & 0.97 & 7.3 & 2012 & 0.97 & 6.9 \\
\hline Finland & 2005 & 1.00 & 3.2 & & & \\
\hline France & 2012 & 0.94 & 2.2 & 2012 & 0.95 & 2.4 \\
\hline Gambia, The & 2008 & 0.21 & 14.7 & & & \\
\hline Georgia & 2012 & 0.58 & 1.7 & 2012 & 0.62 & 1.9 \\
\hline Ghana & 2007 & 0.00 & 9.9 & 2009 & 0.02 & 9.6 \\
\hline Greece & 2011 & 1.00 & 2.4 & 2011 & 1.00 & 2.4 \\
\hline Grenada & 2012 & 0.19 & 12.8 & 2008 & 0.15 & 12.8 \\
\hline Guatemala & 2012 & 0.75 & 7.5 & 2012 & 0.64 & 5.2 \\
\hline
\end{tabular}


Table 3. Global Tariff Exemption Ratios (Cont.)

\begin{tabular}{|c|c|c|c|c|c|c|}
\hline & \multicolumn{3}{|c|}{ WDI } & \multicolumn{3}{|c|}{ WITS } \\
\hline & Year & Ratio & Tariffs & Year & Ratio & Tariffs \\
\hline Honduras & 2009 & 0.71 & 6.5 & 2009 & 0.70 & 6.3 \\
\hline Hungary & 2012 & 0.98 & 2.2 & 2012 & 0.98 & 2.4 \\
\hline Iceland & 2012 & 0.41 & 2.2 & 2011 & 0.41 & 2.3 \\
\hline India & 2009 & 0.17 & 8.4 & 2009 & 0.32 & 10.1 \\
\hline Indonesia & 2007 & 0.55 & 5.4 & 2007 & 0.34 & 3.7 \\
\hline Ireland & 2012 & 0.97 & 2.2 & 2012 & 0.97 & 2.4 \\
\hline Israel & 2012 & 0.55 & 2.1 & 2012 & 0.63 & 2.5 \\
\hline Jamaica & 2011 & 0.59 & 9.8 & 2011 & 0.59 & 9.6 \\
\hline Japan & 2012 & 0.09 & 1.5 & 2012 & 0.08 & 1.5 \\
\hline Jordan & 2009 & 0.66 & 8.9 & 2009 & 0.65 & 8.7 \\
\hline Kenya & 2012 & 0.65 & 11.2 & 2010 & 0.34 & 7.0 \\
\hline Korea, Rep. & 2010 & 0.74 & 8.8 & 2010 & 0.65 & 6.5 \\
\hline Kuwait & 2012 & 0.07 & 4.4 & 2012 & 0.00 & 4.0 \\
\hline Kyrgyz Republic & 2012 & 0.01 & 4.1 & 2012 & 0.02 & 4.1 \\
\hline Lao PDR & 2008 & 0.58 & 13.2 & & & \\
\hline Latvia & 2012 & 0.88 & 2.2 & & & \\
\hline Lebanon & 2007 & 0.43 & 5.7 & & & \\
\hline Luxembourg & 2012 & 1.00 & 2.2 & 2012 & 1.00 & 2.4 \\
\hline Macedonia, FYR & 2012 & 0.76 & 6.4 & 2011 & 0.77 & 6.3 \\
\hline Malaysia & 2009 & 0.91 & 5.8 & 2008 & 0.88 & 4.3 \\
\hline Maldives & 2009 & 0.36 & 20.8 & 2009 & 0.33 & 20.1 \\
\hline Mali & 2011 & 0.14 & 10.2 & 2011 & 0.14 & 10.1 \\
\hline Malta & 2012 & 1.00 & 2.2 & & & \\
\hline Mauritius & 2011 & 0.05 & 1.2 & 2010 & 0.00 & 1.2 \\
\hline Mexico & 2010 & 0.89 & 6.2 & 2010 & 0.88 & 5.6 \\
\hline Moldova & 2012 & 0.41 & 3.7 & 2012 & 0.31 & 3.1 \\
\hline Morocco & 2012 & 0.71 & 9.2 & 2012 & 0.73 & 9.9 \\
\hline Mozambique & 2010 & 0.56 & 7.9 & 2010 & 0.51 & 7.2 \\
\hline Nepal & 2012 & 0.33 & 12.0 & 2012 & 0.31 & 11.7 \\
\hline New Zealand & 2006 & 0.55 & 10.3 & 2006 & 0.18 & 3.4 \\
\hline Nicaragua & 2010 & 0.78 & 5.7 & 2010 & 0.76 & 5.3 \\
\hline Norway & 2012 & 0.05 & 0.6 & 2012 & 0.44 & 1.0 \\
\hline Oman & 2012 & 0.45 & 4.6 & 2009 & 0.44 & 4.6 \\
\hline Pakistan & 2005 & 0.26 & 12.2 & 2005 & 0.26 & 12.2 \\
\hline Paraguay & 2012 & 0.57 & 7.8 & 2011 & 0.47 & 6.6 \\
\hline Peru & 2011 & 0.27 & 1.9 & 2010 & 0.21 & 2.8 \\
\hline Poland & 2012 & 0.98 & 2.2 & 2012 & 0.98 & 2.4 \\
\hline Portugal & 2012 & 1.00 & 2.2 & & & \\
\hline Romania & 2012 & 0.85 & 2.2 & 2012 & 0.86 & 2.4 \\
\hline Russian Federation & 2005 & 0.19 & 9.6 & & & \\
\hline Rwanda & 2012 & 0.64 & 12.9 & 2011 & 0.66 & 12.2 \\
\hline Senegal & 2011 & 0.04 & 8.8 & 2011 & 0.06 & 9.0 \\
\hline
\end{tabular}


Table 3. Global Tariff Exemption Ratios (Cont.)

\begin{tabular}{|c|c|c|c|c|c|c|}
\hline & \multicolumn{3}{|c|}{ WDI } & \multicolumn{3}{|c|}{ WITS } \\
\hline & Year & Ratio & Tariffs & Year & Ratio & Tariffs \\
\hline Seychelles & 2007 & 0.80 & 28.3 & & & \\
\hline Sierra Leone & 2012 & 0.73 & 9.9 & & & \\
\hline Singapore & 2007 & 0.78 & 0.0 & & & \\
\hline Slovak Republic & 2012 & 1.00 & 2.2 & 2012 & 1.00 & 2.4 \\
\hline Slovenia & 2012 & 0.96 & 2.2 & 2012 & 0.97 & 2.4 \\
\hline South Africa & 2012 & 0.29 & 5.7 & 2012 & 0.25 & 5.3 \\
\hline Spain & 2012 & 0.98 & 2.2 & 2012 & 0.98 & 2.4 \\
\hline Sri Lanka & 2011 & 0.40 & 6.3 & 2011 & 0.42 & 6.5 \\
\hline St. Kitts and Nevis & 2011 & 0.05 & 13.1 & 2011 & 0.09 & 13.7 \\
\hline St. Lucia & 2007 & 0.00 & 11.6 & & & \\
\hline St. Vincent and the Grenadines & 2007 & 0.51 & 11.6 & 2007 & 0.52 & 11.8 \\
\hline Suriname & 2010 & 0.52 & 11.9 & 2010 & 0.47 & 10.8 \\
\hline Sweden & 2007 & 0.96 & 3.2 & 2007 & 0.96 & 2.8 \\
\hline Switzerland & 2009 & 0.81 & 2.3 & & & \\
\hline Tanzania & 2012 & 0.46 & 11.7 & 2012 & 0.22 & 8.0 \\
\hline Thailand & 2009 & 0.62 & 4.9 & 2009 & 0.60 & 4.8 \\
\hline Togo & 2010 & 0.40 & 14.5 & 2010 & 0.14 & 10.1 \\
\hline Trinidad and Tobago & 2008 & 0.65 & 10.3 & 2008 & 0.12 & 4.1 \\
\hline Tunisia & 2008 & 0.79 & 16.0 & 2008 & 0.79 & 16.0 \\
\hline Turkey & 2011 & 0.77 & 5.2 & 2011 & 0.75 & 4.9 \\
\hline Uganda & 2012 & 0.48 & 9.1 & 2011 & 0.50 & 8.5 \\
\hline Ukraine & 2012 & 0.26 & 2.6 & 2012 & 0.32 & 2.8 \\
\hline United Kingdom & 2009 & 0.98 & 2.8 & 2009 & 0.98 & 2.8 \\
\hline United States & 2012 & 0.41 & 2.5 & 2012 & 0.31 & 2.1 \\
\hline Uruguay & 2012 & 0.40 & 7.9 & 2012 & 0.43 & 8.2 \\
\hline Vanuatu & 2009 & 0.00 & 18.6 & & & \\
\hline Venezuela, RB & 2005 & 0.38 & 13.6 & & & \\
\hline Zambia & 2009 & 0.31 & 8.6 & 2008 & 0.24 & 9.1 \\
\hline
\end{tabular}

Source: Authors' computation, WDI, and WITS

Note: "Tariffs" indicates the weighted average of MFN rates (\%). Data from WDI are used in the column "WDI" and data from WITS in the column "WITS." 
Table 4. Tariff Exemption Ratios in Country Groupings

\begin{tabular}{lcccccccc}
\hline & $\mathrm{N}$ & Mean & S.D. & Min & p25 & p50 & p75 & Max \\
\hline \hline World & 112 & 0.5352 & 0.3196 & 0 & 0.2946 & 0.5508 & 0.7885 & 1 \\
\hline By Regions & & & & & & & & \\
$\quad$ Africa & 24 & 0.3688 & 0.2920 & 0 & 0.0452 & 0.3530 & 0.6456 & 0.8009 \\
East/Southeast Asia & 9 & 0.5853 & 0.2352 & 0.0874 & 0.5490 & 0.5823 & 0.7443 & 0.9110 \\
$\quad$ South/West Asia & 18 & 0.3832 & 0.2535 & 0.0124 & 0.1739 & 0.3799 & 0.5526 & 0.9603 \\
Europe & 31 & 0.8003 & 0.2859 & 0.0458 & 0.7599 & 0.9634 & 0.9986 & 1 \\
$\quad$ North America & 2 & 0.5255 & 0.1671 & 0.4073 & 0.4073 & 0.5255 & 0.6436 & 0.6436 \\
Latin America & 25 & 0.4992 & 0.2510 & 0 & 0.3397 & 0.5148 & 0.6674 & 0.9693 \\
$\quad$ Pacific & 3 & 0.1952 & 0.3057 & 0 & 0 & 0.0381 & 0.5476 & 0.5476 \\
\hline By RTAs & & & & & & & & \\
AFTA & 6 & 0.6660 & 0.1479 & 0.5490 & 0.5547 & 0.5990 & 0.7832 & 0.9110 \\
COMESA & 8 & 0.4074 & 0.2845 & 0.0309 & 0.1746 & 0.3933 & 0.6456 & 0.8009 \\
EU & 21 & 0.9467 & 0.0876 & 0.6567 & 0.9614 & 0.9773 & 0.9990 & 1 \\
MERCOSUR & 4 & 0.4135 & 0.1131 & 0.3020 & 0.3395 & 0.3909 & 0.4875 & 0.5702 \\
NAFTA & 3 & 0.6462 & 0.2402 & 0.4073 & 0.4073 & 0.6436 & 0.8876 & 0.8876 \\
$\quad$ SAFTA & 8 & 0.3630 & 0.2591 & 0.1172 & 0.2163 & 0.3171 & 0.3799 & 0.9603 \\
\hline
\end{tabular}

Source: Authors' computation

Note: This table reports country-group tariff exemption ratio averages computed using WDI data on the weighted average of MFN rates. 
Table 5. Basic Statistics for Regressions

\begin{tabular}{lccccc}
\hline & Obs & Mean & Std. Dev. & Min & Max \\
\hline \hline Tariff exemption ratio & 112 & 0.535 & 0.320 & 0 & 1 \\
Preference share: RTA & 112 & 0.481 & 0.260 & 0 & 0.991 \\
Preference share: GSP & 112 & 0.054 & 0.100 & 0.000 & 0.351 \\
Export intensity & 112 & 0.300 & 0.231 & 0.030 & 1.733 \\
Preference margin & 112 & 0.009 & 0.019 & -0.040 & 0.084 \\
ln GDP per capita & 112 & 8.709 & 1.454 & 5.710 & 11.551 \\
Weighted-Simple MFN difference & 112 & -0.009 & 0.037 & -0.170 & 0.212 \\
Share of high MFN products & 112 & 0.199 & 0.214 & 0 & 0.909 \\
Share of specific tariff products & 112 & 0.028 & 0.045 & 0 & 0.301 \\
Share of zero MFN products & 112 & 0.275 & 0.244 & 0 & 1.000 \\
Consolidated dummy & 112 & 0.625 & 0.486 & 0 & 1 \\
\hline
\end{tabular}

Source: Authors' computation 
Table 6. Correlation with Basic Elements

\begin{tabular}{lcccc}
\hline & $(\mathrm{I})$ & $(\mathrm{II})$ & $(\mathrm{III})$ & $(\mathrm{IV})$ \\
\hline \hline Preference share: RTA & $0.756^{* * *}$ & $0.693^{* * *}$ & $0.643^{* * *}$ & $0.584^{* * *}$ \\
& {$[0.103]$} & {$[0.108]$} & {$[0.109]$} & {$[0.112]$} \\
Preference share: GSP & & & $0.962^{* * *}$ & $0.945^{* * *}$ \\
& & & {$[0.230]$} & {$[0.222]$} \\
Export intensity & & $0.265^{* *}$ & & $0.253^{* *}$ \\
& & {$[0.120]$} & & {$[0.102]$} \\
Constant & $0.172^{* * *}$ & $0.122^{* *}$ & $0.174^{* * *}$ & $0.127^{* *}$ \\
& {$[0.059]$} & {$[0.057]$} & {$[0.060]$} & {$[0.057]$} \\
\hline Number of observations & 112 & 112 & 112 & 112 \\
R-squared & 0.3800 & 0.4139 & 0.4624 & 0.4934 \\
\hline
\end{tabular}

Note: The dependent variable is the tariff exemption ratio computed using WDI data on the weighted average of MFN rates. ***,**, and * indicate $1 \%, 5 \%$, and $10 \%$ significance, respectively. Robust standard errors are in parentheses. 
Table 7. Correlation with Advanced Elements

\begin{tabular}{|c|c|c|c|}
\hline & (I) & (II) & (III) \\
\hline \multirow[t]{2}{*}{ Preference share: RTA } & $0.490 * * *$ & $0.482 * * *$ & $0.526 * * *$ \\
\hline & [0.129] & {$[0.128]$} & {$[0.121]$} \\
\hline \multirow[t]{2}{*}{ Preference share: GSP } & $0.808 * * *$ & $0.760 * * *$ & $0.814 * * *$ \\
\hline & {$[0.246]$} & {$[0.253]$} & {$[0.283]$} \\
\hline \multirow[t]{2}{*}{ Export intensity } & $0.255^{* * *}$ & $0.247 * *$ & $0.282 * * *$ \\
\hline & [0.098] & {$[0.103]$} & [0.098] \\
\hline \multirow[t]{2}{*}{ Preference margin } & $2.579 *$ & $2.646^{*}$ & $4.700 * * *$ \\
\hline & {$[1.550]$} & {$[1.512]$} & {$[1.645]$} \\
\hline \multirow[t]{2}{*}{ ln GDP per capita } & & 0.007 & 0.013 \\
\hline & & {$[0.020]$} & {$[0.021]$} \\
\hline \multirow[t]{2}{*}{ Weighted-Simple MFN difference } & & & $2.064 * * *$ \\
\hline & & & {$[0.626]$} \\
\hline \multirow[t]{2}{*}{ Share of high MFN products } & & & $0.254 * *$ \\
\hline & & & [0.128] \\
\hline \multirow[t]{2}{*}{ Share of specific tariff products } & & & -0.274 \\
\hline & & & {$[0.471]$} \\
\hline \multirow[t]{2}{*}{ Share of zero MFN products } & & & -0.058 \\
\hline & & & {$[0.116]$} \\
\hline \multirow[t]{2}{*}{ Consolidated dummy } & & & 0.043 \\
\hline & & & {$[0.052]$} \\
\hline \multirow[t]{2}{*}{ Constant } & $0.155^{* * *}$ & 0.102 & -0.039 \\
\hline & [0.059] & {$[0.165]$} & [0.193] \\
\hline Number of observations & 112 & 112 & 112 \\
\hline R-squared & 0.5067 & 0.5074 & 0.5566 \\
\hline
\end{tabular}

Note: The dependent variable is the tariff exemption ratio computed using WDI data on the weighted average of MFN rates. $* * *, * *$, and * indicate $1 \%, 5 \%$, and $10 \%$ significance, respectively. Robust standard errors are in parentheses. 
Figure 1. Trends in Tariff Exemption Ratios for Selected Countries

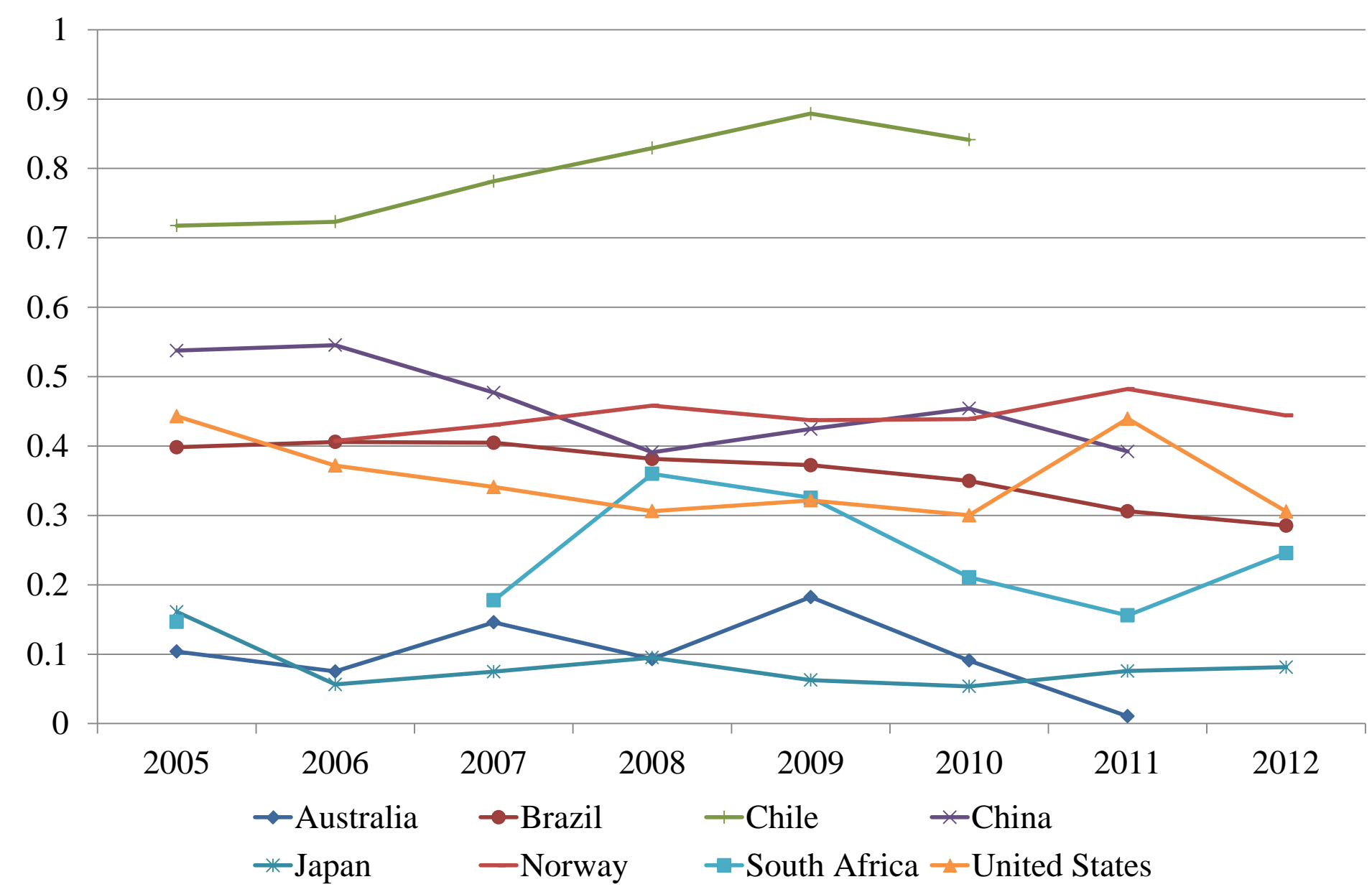

Source: Authors' computation.

Note: In this figure, we employ the tariff exemption ratio computed using WITS data on the weighted average of MFN rates. 
Figure 2. Quasi-Decomposition of Total Imports

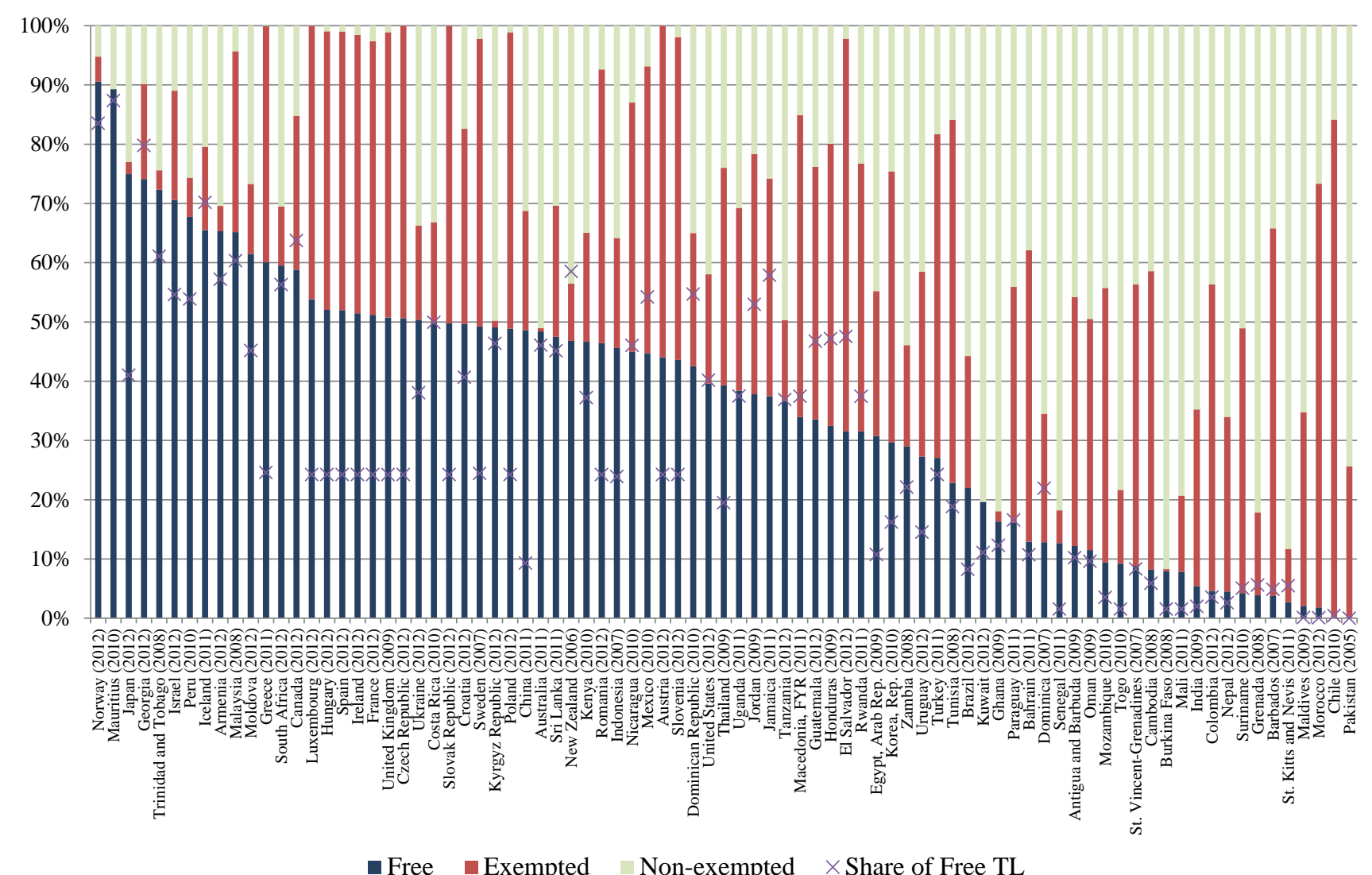

Source: Authors' computation.

Note: In this figure, we employ the tariff exemption ratio computed using WITS data on the weighted average of MFN rates. "Free" indicates the share of imports of products with zero MFN rates out of total imports. "Exempted" and "Non-exempted" refer to the shares of the exemption-basis preferential and non-preferential imports out of total imports, respectively. "Share of Free TL" is the share of the tariff line-level products with zero MFN rates in total. 


\section{Appendix A. Equivalence of Equations (2) and (5)}

In this appendix, we demonstrate that equation (2) is equivalent to equation (5). The weighted average of MFN rates can be defined as follows:

$$
\begin{gathered}
\text { Weighted Average of MFN Rates } \equiv \sum_{i}\left\{\left(\frac{I_{i}^{M}+I_{i}^{P}}{\sum_{k}\left(I_{k}^{M}+I_{k}^{P}\right)}\right) \cdot t_{i}^{M}\right\} \\
=\sum_{i}\left\{\frac{\left(I_{i}^{M}+I_{i}^{P}\right) \cdot t_{i}^{M}}{\sum_{k}\left(I_{k}^{M}+I_{k}^{P}\right)}\right\}=\frac{\sum_{i}\left\{t_{i}^{M}\left(I_{i}^{M}+I_{i}^{P}\right)\right\}}{\sum_{k}\left(I_{k}^{M}+I_{k}^{P}\right)} .
\end{gathered}
$$

Therefore, the denominator in the second term in equation (5) can be summarized as follows:

$$
\begin{aligned}
& \text { (Weighted Average of MFN Rates) } \times(\text { Total Imports) } \\
& \qquad=\frac{\sum_{i}\left\{t_{i}^{M}\left(I_{i}^{M}+I_{i}^{P}\right)\right\}}{\sum_{k}\left(I_{k}^{M}+I_{k}^{P}\right)} \times \sum_{k}\left(I_{k}^{M}+I_{k}^{P}\right)=\sum_{i} t_{i}^{M}\left(I_{i}^{M}+I_{i}^{P}\right)
\end{aligned}
$$

This term is exactly the same as the denominator in the second term in equation (2). Furthermore, by definition, the numerator in the second term in equation (2) is the same as "Total Revenues from Import Duties," which is the numerator in the second term in equation (5). As a result, equation (5) is equivalent to equation (2). 


\section{Appendix B. Several Additional Tables}

Table B1. Difference in Tariff Exemption Ratios According to Data Sources

\begin{tabular}{cc}
\hline & Difference \\
\hline \hline $\mathrm{N}$ & 83 \\
Mean & 0.027 \\
S.D. & 0.107 \\
Min & -0.398 \\
p25 & -0.003 \\
p50 & 0.005 \\
p75 & 0.047 \\
Max & 0.531 \\
\hline
\end{tabular}

Note: This table reports various statistics on the difference between tariff exemption ratios based on WDI and WITS data.

Table B2. Share of Products with Zero MFN Rates

\begin{tabular}{lcccccccc}
\hline & 2005 & 2006 & 2007 & 2008 & 2009 & 2010 & 2011 & 2012 \\
\hline \hline Australia & $48 \%$ & $48 \%$ & $46 \%$ & $46 \%$ & $46 \%$ & $46 \%$ & $46 \%$ & \\
Brazil & $7.1 \%$ & $7.0 \%$ & $7.1 \%$ & $7.3 \%$ & $7.4 \%$ & $7.5 \%$ & $7.5 \%$ & $8.2 \%$ \\
Chile & $0.4 \%$ & $0.4 \%$ & $0.5 \%$ & $0.5 \%$ & $0.5 \%$ & $0.5 \%$ & & \\
China & $8.5 \%$ & $8.6 \%$ & $8.5 \%$ & $8.5 \%$ & $8.2 \%$ & $8.4 \%$ & $9.3 \%$ & \\
Japan & $41 \%$ & $42 \%$ & $42 \%$ & $42 \%$ & $42 \%$ & $42 \%$ & $42 \%$ & $41 \%$ \\
Norway & & $84 \%$ & $84 \%$ & $83 \%$ & $84 \%$ & $84 \%$ & $84 \%$ & $84 \%$ \\
South Africa & & & $54 \%$ & $54 \%$ & $56 \%$ & $57 \%$ & $56 \%$ & $56 \%$ \\
United States & $41 \%$ & $41 \%$ & $40 \%$ & $40 \%$ & $40 \%$ & $40 \%$ & $40 \%$ & $40 \%$ \\
\hline
\end{tabular}

Source: WITS. 
Table B3. Fractional Logit Model

\begin{tabular}{lcc}
\hline & WDI & WITS \\
\hline \hline Preference share: RTA & $2.397^{* * *}$ & $3.056^{* * *}$ \\
Preference share: GSP & {$[0.607]$} & {$[0.615]$} \\
& $4.434^{* *}$ & 1.568 \\
Export intensity & {$[1.743]$} & {$[1.789]$} \\
& $1.536^{* * *}$ & 1.151 \\
Preference margin & {$[0.587]$} & {$[0.785]$} \\
& $23.034^{* * *}$ & $19.167^{* *}$ \\
ln GDP per capita & {$[8.749]$} & {$[9.625]$} \\
& 0.044 & -0.102 \\
Weighted-Simple MFN difference & {$[0.106]$} & {$[0.114]$} \\
Share of high MFN products & $9.989 * * *$ & $15.645^{* *}$ \\
Share of specific tariff products & {$[3.066]$} & {$[6.594]$} \\
Share of zero MFN products & $1.210^{* *}$ & 0.581 \\
Consolidated dummy & {$[0.569]$} & {$[0.809]$} \\
& -1.592 & $13.628^{* * *}$ \\
Number of observations & {$[2.629]$} & {$[5.168]$} \\
Log pseudolikelihood & -0.315 & $-1.050^{*}$ \\
\hline
\end{tabular}

Note: $* * *, * *$, and $*$ indicate $1 \%, 5 \%$, and $10 \%$ significance, respectively. Robust standard errors are in parentheses. The dependent variables in columns "WDI" and "WITS" are tariff exemption ratios computed by employing the data on the weighted average of MFN rates from WDI and WITS, respectively. 
Figure B1. Kernel Density of Tariff Exemption Ratio

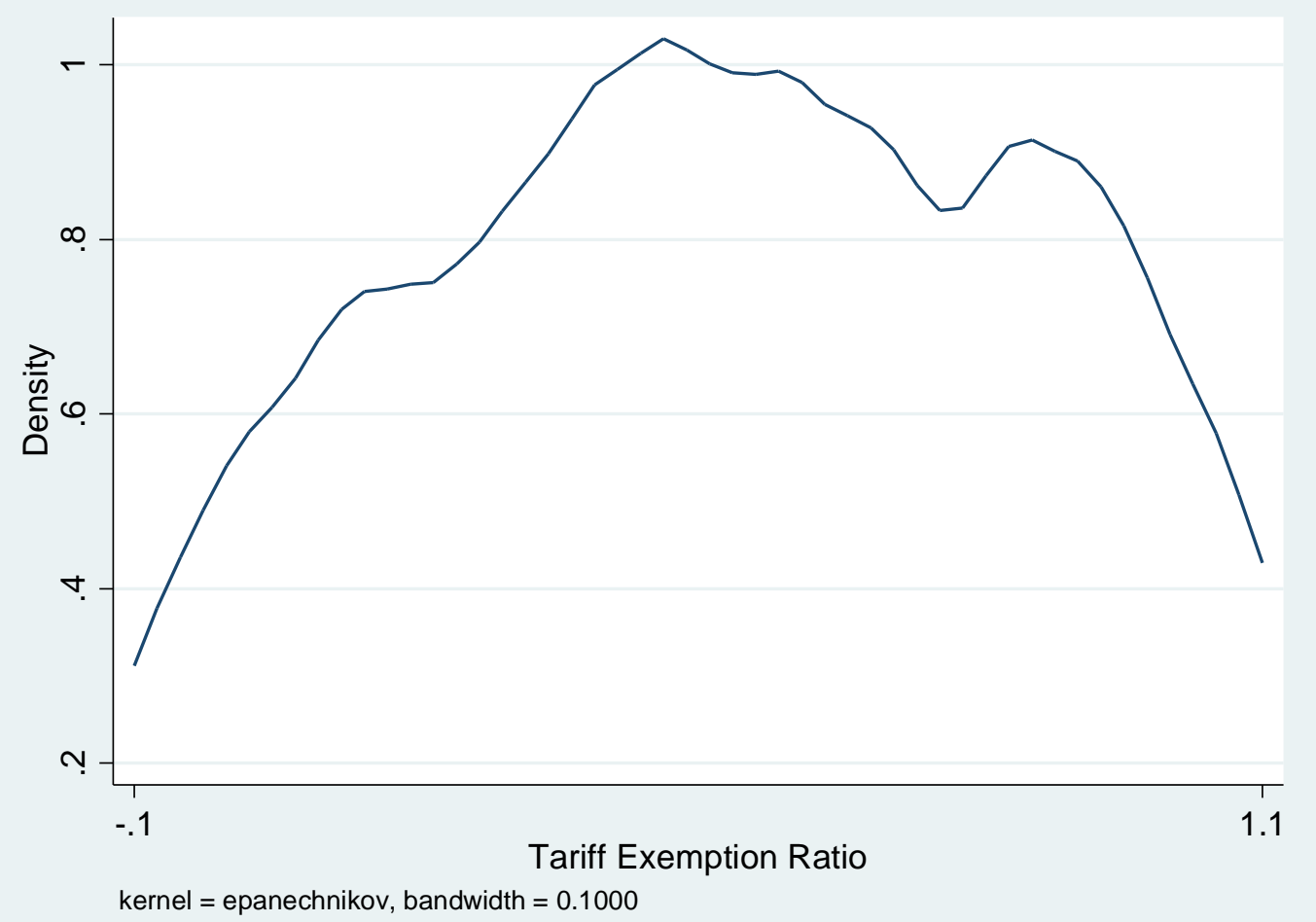

Source: Authors' compilation.

Note: The tariff exemption ratio lies in the unit interval, i.e., $[0,1]$. 